\title{
A structured mixed method process evaluation of a randomized controlled trial of Individual Placement and Support (IPS)
}

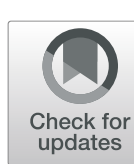

Tonje Fyhn ${ }^{1 *}$ (D) Kari Ludvigsen², Silje E. Reme ${ }^{3}$ and Frederieke Schaafsma ${ }^{4}$

\begin{abstract}
Background: Individual Placement and Support (IPS) is an evidence-based work rehabilitation program helping people with moderate to severe mental illness to obtain ordinary employment. Although IPS has proven superior to other work rehabilitation programs, in many studies, the majority of the participants remain unemployed. Structured process evaluations of IPS that use mixed methods are scarce, although they could identify implementation aspects that may enhance its effect. The aim of the current study is to assess reach, fidelity, and identify barriers and facilitators to implement IPS.

Methods: The process evaluation was conducted alongside a randomized controlled trial including six IPS centers, comparing IPS with treatment as usual in a population of patients in treatment for moderate to severe mental illness. Mixed methods were used in the process evaluation, including focus group interviews with service providers, individual interviews and survey data from participants, and fidelity reviews using the validated IPS Fidelity Scale.

Results: The intervention reached the intended target group. All centers reached fair to good fidelity according to the IPS Fidelity Scale within the project period (range 97-109, SD 8.1) (see Table 5). Certain fidelity items indicated implementation issues related to employer contact, community-based services, and integration with health services. Survey data showed that less than half of the participants regarded their illness as a barrier for participating in IPS and that freedom of disclosure was important. Participant interviews gave further insight into the role of the IPS specialist, emphasizing their availability and consistent job focus.
\end{abstract}

Conclusions: Indications of implementation challenges across centers during the first year suggest special attention should be given to these aspects in an early phase to ensure higher fidelity from the start and thus enhance the effectiveness of IPS. The IPS specialist played an important role for participants and was described as positive, pushing in a positive way, and encouraging. More knowledge on the characteristics of successful IPS specialists could further enhance the effectiveness of the intervention.

Trial registration: The study was registered on clinicaltrials.gov prior to the inclusion period (reg.no: NCT01964092, registered 17/07/2013).

Keywords: IPS, Process evaluation, Recovery, Psychiatric disorders, Mental health services

\footnotetext{
* Correspondence: tofy@norceresearch.no

${ }^{1}$ NORCE Norwegian Research Centre, Postboks 7810, 5020 Bergen, Norway

Full list of author information is available at the end of the article
}

C C The Author(s). 2020 Open Access This article is licensed under a Creative Commons Attribution 4.0 International License, which permits use, sharing, adaptation, distribution and reproduction in any medium or format, as long as you give appropriate credit to the original author(s) and the source, provide a link to the Creative Commons licence, and indicate if changes were made. The images or other third party material in this article are included in the article's Creative Commons licence, unless indicated otherwise in a credit line to the material. If material is not included in the article's Creative Commons licence and your intended use is not permitted by statutory regulation or exceeds the permitted use, you will need to obtain permission directly from the copyright holder. To view a copy of this licence, visit http://creativecommons.org/licenses/by/4.0/ The Creative Commons Public Domain Dedication waiver (http://creativecommons.org/publicdomain/zero/1.0/) applies to the data made available in this article, unless otherwise stated in a credit line to the data. 


\section{Contributions to the literature}

- The study describes a structured process evaluation of IPS using concepts from the implementation literature, which is lacking in previous IPS studies.

- The study uses mixed methods to gain a thorough understanding of barriers and facilitators to implementation and participation.

- The study supports the recovery notion that people with severe mental illness who are motivated to find employment should be offered help to achieve this.

- The study suggests a need for weighting IPS fidelity items according to their association with employment outcomes.

\section{Background}

Mental disorders represent a significant barrier to employment [1]. The WHO's “Mental Health Action Plan 2013-2020" advices the use of so-called multisectoral approaches to treatment, characterized by coordinated services to ensure not only basic health treatment, but also access to employment [2]. One such multisectoral approach is the vocational service Individual Placement and Support (IPS). IPS is an evidence-based approach helping individuals with severe mental illness to obtain ordinary employment [3]. It is based on a recovery approach to mental illness, emphasizing consumerorientation, social support, and integration of services [4]. It is based on eight principles: Seeking competitive employment, rapid job search, systematic job development, integrated services, benefits planning, no exclusion, timeunlimited support, and participant preferences [5]. Participants are assigned an IPS specialist who provides face-toface counseling, who is trained in the method, and who helps them get in touch with a potential employer within 30 days. The job search is guided by the participant's preferences. The IPS specialist provides time-unlimited supports and follows up missed appointments with participants. The supports continue as needed after obtaining employment. The IPS specialist is integrated in participants' health treatment team, in order to ensure coordinated services that facilitate work participation. The IPS specialist should spend $65 \%$ or more of their time outside the office, to ensure active follow-up of participants and face-to-face networking with employers in the community.

The IPS principles are operationalized in an implementation manual [6], which describes in detail the resources and preparations needed at different levels of the involved institutions to successfully implement the intervention. The principles are quantified in the validated IPS Fidelity Scale, which measures adherence to the method across different cultural contexts [7]. IPS programs obtaining high scores on this scale, as measured by evaluators, obtain higher shares of employment in ordinary jobs [8-10]. Through several experimental studies, the IPS method has proved more effective than traditional employment services, providing a robust empirical base for implementation across a wide variety of cultural contexts [11].

Although IPS has consistently proved effective, the majority of participants do not obtain employment [12-17]. Perhaps more thorough process evaluations or implementation studies could shed light on specific barriers and facilitators to be targeted in order to enhance employment outcomes. Process evaluations aim to improve the external validity of the outcome evaluation [18] and should describe what components of a given intervention are effective, for whom, and under what conditions $[19,20]$. However, structured process evaluations of IPS are scarce. A recent review on implementation studies of supported employment revealed that the investigation of implementation issues take widely different approaches, from reflections based on anecdotes to semi-structured interviews and surveys [21]. The lack of common approaches makes it difficult to get an overview of implementation challenges that are generic across contexts, or specific to certain contexts. Such knowledge could enhance future IPS implementation efforts, particularly for piloting IPS for new target groups, such as patients with chronic pain, marginalized young people, and refugees [22, 23]. The process evaluation in the current study focused on assessing reach, fidelity of intervention delivery, and exploring barriers and facilitators to implementation and participation. These implementation measures were selected in accordance with the specifications in the governmental commission that initiated the study, and with recommendations found in Linnan and Steckler's framework for conceptualizing process evaluations of public health interventions and research [19]. These authors define reach as the extent to which the intended target group actually participates in the intervention, and fidelity is defined as the extent to which the intervention was carried out as planned. Barriers and facilitators are defined in the current study as factors that obstruct or enable implementation of evidence-based practices [24].

The process evaluation was conducted alongside the randomized controlled trial of IPS in Norway $[15,25]$, and its function was to complement the results from the RCT, as well as enhance the effect of future IPS implementation efforts [15]. The aim of the current study is to answer the following research questions:

- Was the target group reached?

- What are barriers and facilitators to implementation as indicated by fidelity reviews and focus group interviews with service providers? 
- What are barriers and facilitators to participation as indicated by follow-up surveys and individual interviews with participants?

\section{Methods}

The process evaluation used mixed methods in the effort to identify barriers and facilitators to implement IPS, and the interplay between intervention components $[26,27]$. Its methodological structure is QUAN + qual, meaning that quantitative and qualitative data was collected simultaneously, but the starting point for the analyses was the quantitative data [28].

\section{About the IPS trial}

The IPS trial included an outcome evaluation, a process evaluation, and a cost/benefit analysis [25]. Participants were randomized to an intervention group receiving IPS in addition to treatment as usual (TAU), or to a control group receiving only TAU. Randomization was stratified by each pilot center. Results from the outcome evaluation showed that IPS was more effective than TAU, and the intervention group also showed improvements on the secondary outcomes of self-reported health and depressive symptoms, quality of life, and subjective health complaints [15]. The cost-benefit analysis showed that the intervention was not financially sustainable in the short term, but is likely to achieve this within a few years if the employment rate is sustained (ibid).

\section{Process measures}

The process evaluation was designed as a summative, and not a formative, evaluation, meaning that its purpose was to generate knowledge about the implementation process of a standardized intervention [26]. An overview of the process measures is provided in Table 1.

Reach describes whether the study population corresponded to the pre-defined target population for the intervention. Barriers and facilitators aim to identify problems as well as helpful factors in the implementation of and

Table 1 Data sources of the selected process measures at participant and service provider level

\begin{tabular}{ll}
\hline Process measure & Data source \\
\hline $\begin{array}{l}\text { Participant level } \\
\text { Reach/population } \\
\text { characteristics } \\
\text { Barriers and facilitators }\end{array}$ & $\begin{array}{l}\text { Baseline survey and Mini-National } \\
\text { Neuropsychiatric Interviews (M.I.N.I) } \\
\text { 6-month follow-up survey, individual } \\
\text { interviews }\end{array}$ \\
$\begin{array}{l}\text { Service provider level } \\
\text { Barriers and facilitators }\end{array}$ & $\begin{array}{l}\text { Focus group interviews with IPS } \\
\text { specialists, and fidelity reviews from } \\
\text { each center } \\
\text { Fidelity }\end{array}$ \\
\hline
\end{tabular}

participation in the intervention, as reported by IPS specialists and intervention participants. Fidelity measures adherence to the IPS method from service providers, by using the IPS Fidelity Scale [9].

\section{Study population}

Data was collected from two populations: participants in the intervention group of the RCT and service providers.

\section{Intervention participants}

A total of 227 participants were randomized to the intervention group at inclusion, and 96 of these returned the 6-month follow-up questionnaire. Inclusion criteria for participants in the RCT were being in treatment for moderate to severe mental illness, having a desire to work, and understanding Norwegian well enough to respond to questionnaires. There were no significant differences between the intervention and control groups at baseline [15].

\section{Service providers}

Data from service providers was collected through fidelity reviews from each center and focus group interviews with the IPS specialist team at each center. Two focus groups consisted of three informants, and four groups consisted of five informants.

\section{Data collection \\ Reach}

Reach was measured through quantitative baseline survey data as well as results from the Mini-International Neuropsychiatric Interview (M.I.N.I), a short, structured diagnostic interview [29] which was conducted at inclusion.

\section{Barriers and facilitators to participate in IPS}

Data was collected through individual interviews with intervention participants, as well as items in the 6month follow-up questionnaire. Informants were recruited based on their written consent in the 6-month follow-up questionnaire and were randomly selected from a computer-generated list of participants who reported to be "less satisfied" to "very satisfied" as indicated in the questionnaire. Twelve participants agreed to be interviewed. The interviews followed a semistructured interview guide and lasted up to $20 \mathrm{~min}$. Interviews were conducted by author KL and a research assistant. All participants who were interviewed signed an informed and written consent for this particular substudy. Items included in the 6-month follow-up survey were constructed for the current study and were not validated. Items included a list of statements concerning six proposed barriers and six proposed facilitators of participation (yes/no), which articulated aspects of IPS that 
differed from ordinary work rehabilitation programs, or other aspects of the intervention that could possibly obstruct or enable participation for this target group. An open-ended response category was added under each list. Satisfaction with the IPS specialist was measured through the item "How satisfied are you with your IPS specialist?" Perceived usefulness was measured through the question "How useful has it been for you to participate in IPS?" Response categories for each question ranged from $1=$ very dissatisfied/not useful at all to $5=$ very satisfied/useful.

\section{Barriers and facilitators to implement IPS}

Data was collected through focus group interviews with IPS teams, and fidelity reviews. IPS specialists and team leaders were asked to participate in interviews as a team, which were conducted by author KL at all six IPS centers. The interviews followed a semi-structured interview guide and lasted for approximately $1.5 \mathrm{~h}$. The interview guide was developed by drawing on experiences from a previous project with high resemblance to the current and by assessing specifications in the governmental commission. Interviews were recorded on tape and transcribed before analyses. All informants were informed of the purpose of the interviews, that participation was voluntary, and of their right to withdraw at any time.

The fidelity reviews were carried out at each center approximately 1 year into the study period by a trained evaluator team who followed instructions in the IPS Fidelity Review Manual [6]. Low overall fidelity scores indicate implementation challenges, and low scores on single items indicate what those challenges are. The scrutiny of the IPS Fidelity scale enables a more finegrained examination of possible implementation issues than general scales of program adherence. Fidelity measurements are therefore included as indicators of barriers and facilitators to implementation, complemented by focus group interview data.

\section{Data analysis}

To investigate reach, descriptive analyses were conducted on baseline data and M.I.NI. results, using SPSS 25 and Excel (2017).

Quantitative and qualitative data on barriers and facilitators were collated through the following steps, performed separately for each participant group: (1) quantitative data was analyzed, (2) qualitative data was analyzed, and (3) survey items or fidelity items that were particularly low or high were used as an indicator to select themes from the interviews that could further describe these issues. Lists of themes derived from the interviews are included in the supplementary material.

\section{Barriers and facilitators to participate in IPS}

Descriptive analyses were conducted on survey data using SPSS 25. To identify barriers and facilitators, results were interpreted by looking for frequently occurring responses in the lists of barriers and facilitators, or unevenly distributed responses to the satisfaction/usefulness items.

Qualitative data was analyzed through a deductive approach, using thematic analysis as described by Boyatzis [30] and Joffe and Yardley [31]. A coding scheme was constructed based on topics in the interview guide and expanded or revised according to recurring topics in the data. The interviews were studied repeatedly and categorized according to this scheme. The analysis focused on manifest content rather than latent phenomena [31], to facilitate bridging of the qualitative and the quantitative data [30]. The unit of analysis was sentences or shorter paragraphs where several sentences described the same topic. Author KL conducted the first round of analyses, and TF supplied and adjusted themes in the second round of analyses. The two authors agreed on the final themes to be included in the study.

Quantitative and qualitative results were collated through the steps described above, using quantitative findings as a lens to select themes from the qualitative results. Some interview themes contained descriptions that were specific to the Norwegian context; others lacked substance and coherence. These were not included in the subsequent analysis, but were described in the final report to the study commissioner [32].

\section{Barriers and facilitators to implementation}

The same analytic approach was used for the focus group interviews.

Fidelity reviews were summarized in an Excel table where mean, minimum, and maximum scores and disparities between high-performing and less-performing centers were calculated. Items with particularly low or high scores across centers 1 year into the study period were assumed to indicate implementation barriers or facilitators.

\section{Results \\ Reach}

The target group for the trial, as defined in the governmental commission of the study, were people in treatment for moderate to severe mental illness in secondary care. The diagnostic screening of participants at inclusion showed that $51 \%$ of the participants suffered from severe mental illness (psychosis or bipolar disorder) and $49 \%$ fulfilled criteria for moderate mental illness (primarily affective disorders). This indicates that the study population corresponds to the pre-defined target group. 
An overview of study population characteristics is provided in Table 2.

The study population was relatively young $(x=35$, SD 10.7) and education level was low. Nearly half of the participants had experienced violence, and one third had been involuntarily committed to a psychiatric hospital. Mean of previous years worked in main occupation was 7 (SD 7). The mean rating of health-related quality of life, measured by the EQ-5D visual analogue scale, was 58 (SD 18.3).

\section{Barriers and facilitators to participate in IPS}

Table 3 shows results from the barriers and facilitators to participation lists. Open-ended response categories were provided, but they did not generate additional barriers or facilitators.

Two of the most frequently cited facilitators among participants regarded the IPS specialist's role: $94 \%$ of respondents agreed with the statement "Knowing that the IPS specialist was available for me was helpful," while $81 \%$ agreed with the statement "The regular follow-up from the IPS specialist was helpful."

Responding to a separate item regarding the IPS specialist, $78 \%$ reported to be satisfied, while $13 \%$ reported to be dissatisfied. Nine percent reported to be neither dissatisfied nor satisfied $(n=78 ; x=4$ SD 1.11).

All over, participants were very happy with the role of the IPS specialist. Participant interviews gave further insight into the IPS specialist's role, emphasizing their availability, support, and consistent job focus. When talking about availability, informants emphasized that

Table 2 Characteristics of the intervention group at baseline

\begin{tabular}{lllll}
\hline Variable & $\%$ & $\boldsymbol{n}$ & Mean & SD \\
\hline Age & & 185 & 35 & 10.7 \\
Gender (female) & 51 & 185 & & \\
Higher education & 24 & 182 & & \\
Reading/writing disabilities & 15 & 182 & & \\
Years of employment experience & & 154 & 7.4 & 7 \\
Health-related quality of life (EQ-VAS; 0-100) & & 172 & 58 & 18.3 \\
Functioning (WHODAS; 0-48) & & 179 & 22 & 14 \\
Previously experienced violence & 48 & 180 & & \\
Previously involuntarily committed & 31 & 173 & & \\
Years with mental health complaints & & 141 & 10.8 & 9.2 \\
Psychiatric diagnoses (M.I.N.I. Interviews) & & & & \\
$\quad$ Recurrent depression & 49 & 140 & & \\
$\quad$ Psychosis & 41 & 142 & & \\
Anxiety & 60 & 141 & & \\
Substance addiction & 15 & 165 & & \\
Severe mental illness & 51.4 & 146 & & \\
Moderate mental illness & 48.6 & 146 & & \\
\hline
\end{tabular}

the IPS specialist was quick to respond and to express their availability:

She is really good, really efficient. Supportive, calls and asks me to call back, to call on her spare time. If it's a good time it's a good time, if it's not a good time she calls me back up again. It's been really nice. (Informant 2)

I think he's been really available, because even if he doesn't answer my call immediately, he calls me back up, he is always there for me if anything comes up. So yes...I feel I have received very, very good follow-up from him. So I am very happy. (Informant 8 )

Some participants said that the IPS specialist "pushed" them to keep going with the job search, and some had been confronted with their lack of motivation. This resulted in taking a more active role in the job search:

It wasn't a threat, but they said we can't help you if you're not interested. They deserved an honest answer to that. It was the best question I could have received, instead of them saying 'We're not wasting time on this...' I woke up. (Informant 10)

It has been positive for me to start working, yes. But I do feel there is a small pressure and that I have to push myself to say yes to working. I am supposed to start working and not sit at home. And I did get a job, so maybe it's good that they push a little. (Informant 2)

One participant described how being listened to in the process was important:

If he has come with a job suggestion and I have said that this is not for me, because I will not function well there, he has just put it away immediately, he is very accommodating like that. (Informant 4)

There were a few exceptions to the positive descriptions of the IPS specialist's role. Two of the informants who were less satisfied with the intervention described the interaction with the IPS specialist as challenging.

Another facilitator for participation indicated by survey data was the freedom to disclose or not: $93 \%$ of respondents agreed that "Being able to choose whether or not to be open about my illness" was helpful. The interviews indicated that for some participants, choosing to disclose expanded the possibilities for practical help in the job search: 
Table 3 Percentage and number of respondents agreeing to the statements about facilitators and barriers

\begin{tabular}{|c|c|c|c|c|c|}
\hline Facilitators for participation & Yes & $n$ & Barriers for participation & Yes & $n$ \\
\hline It was helpful that progress was quicker than other vocational services & $65 \%$ & 77 & Progress was made too quickly & $13 \%$ & 76 \\
\hline Knowing the IPS specialist was available was helpful & $92 \%$ & 77 & It was too time-consuming & $9 \%$ & 77 \\
\hline The action steps along the way were specific, and this was helpful & $79 \%$ & 76 & I had challenges with my IPS specialist & $8 \%$ & 76 \\
\hline Freedom of disclosure was helpful & $92 \%$ & 76 & My illness was a barrier & $43 \%$ & 77 \\
\hline The support plan I made with the IPS specialist when I got a job was helpful & $52 \%$ & 64 & IPS was not what I expected & $17 \%$ & 77 \\
\hline The regular follow-up from the IPS specialist in the job search was helpful & $79 \%$ & 72 & $\begin{array}{l}\text { Getting to the different places } \\
\text { (to meet employers or IPS specialist) }\end{array}$ & $9 \%$ & 76 \\
\hline
\end{tabular}

Yes, it's very nice because the IPS specialist can call around for me, I have anxiety about talking on the phone sometimes. And she is with me in the conversations with employers so that I understand what is being said, and she can also inquire about salary. (Informant 2)

One participant reflected on the positive aspects of disclosing to potential employers:

It might be that some employers think that they want to support it because it is kind of a good cause to help people get a job that maybe have a history of illness or have had problems, and because of that they can get a job. (Informant 7)

Most of the proposed barriers were not supported by participants. However, the most agreed-upon statement was "My illness was a barrier" $(46 \%, n=95)$. Considering the target group of the intervention, this number is not particularly high. Informants described illness factors mostly in the context of having the IPS follow-up tailored to their health condition. One in six participants agreed to the statement "IPS was not what I expected" $(17 \%, n=77)$. Examples of this were found in the interviews. While some participants were positively surprised by the intervention, others described being disappointed due to high expectations.

I was promised employment within 6 weeks, and now I have waited for 13-14 months (...). I had expectations about follow-up from IPS specialist and close cooperation between my doctor, the District Psychiatric Center, and a permanent position with full salary. And none of it has happened. (Informant 6)

One informant stated that the follow-up was simply different from what he had expected regarding his own involvement:

Uuuhm, but the only expectation I did have that turned out not to be correct was that I kind of thought they had some sort of obligation to help me find a job so I didn't have to do such an effort myself. But that was totally wrong. (...) It's not like I can nag them and say 'Hey, find me a job', it's more like they come alongside and back me up on the things I manage to do. (Informant 5)

Two items measuring satisfaction and perceived usefulness were included as indicators of barriers and facilitators to participation, as low scores on these measures could indicate poor quality in intervention delivery, and/ or low engagement with the intervention among participants (Table 4). However, participants were overall satisfied with the intervention $(n=95 ; x=3.95$ SD 0.97$)$ and also found it useful ( $n=96 ; x=3.96$ SD 1.06).

Participant interviews provided further insight about this. Informants said that IPS had made them aware of their own competence and preferences. Most informants reported that IPS had increased the frequency of sending applications and that they had learned more about going to job interviews. They emphasized that the focus on employment had been central in the follow-up:

Table 4 Participants' satisfaction and perceived usefulness of the intervention

\begin{tabular}{lll}
\hline & $\%$ & $\boldsymbol{n}$ \\
\hline General satisfaction $(\boldsymbol{n}=\mathbf{7 8})$ & 1 & 1 \\
Dissatisfied & 9 & 7 \\
Not very satisfied & 18 & 14 \\
A little satisfied & 37 & 29 \\
Pretty satisfied & 35 & 27 \\
Very satisfied & & \\
Usefulness $(\boldsymbol{n}=\mathbf{7 8})$ & 4 & 3 \\
Not useful at all & 4 & 3 \\
Not very useful & 24 & 19 \\
A little useful & 30 & 23 \\
Pretty useful & 39 & 30 \\
Very useful & & \\
\hline
\end{tabular}


I haven't got a job offer, but now I apply for jobs in a different way. I have been on many interviews, so that has improved as a result of this follow-up (...). I learned how to write an application, about motivation, qualities.... (Informant 11)

The first thing we did was to go over what kind of jobs I wanted, then we got my CV sorted out, how to write an application, and have everything ready for sending the application. (...) And then we went out into the job market. We went step by step, one thing after another, in the right order. (Informant 10)

\section{Barriers and facilitators to implement IPS}

Barriers and facilitators to implementation were examined using the IPS Fidelity Scale and focus group interviews with IPS teams. Results are presented in Table 5. All six centers had reached fair or good fidelity at this point, with scores ranging between 97 (see Table 5) and 109 (median 99.5), with 125 as the highest attainable score, and 74 as the cut-off score for being IPS. Single items were rated on a range from 1 to 5 , where item scores 1-3 indicate no or poor implementation.

Items with low scores across centers were "Communitybased services" ( $x=1)$ and "Job development-frequency" $(x=2)$. To receive a top score on "Community-based services," the IPS specialists must spend $65 \%$ or more of their time outside the office, following up participants in their local area. This should be seen in relation to the item "Job development-frequency," indicating frequency of contact with employers in order to develop a broad employer network. The IPS specialists reported in the interviews that it had taken quite some time to develop and understand their role and that prioritizing tasks was demanding, as expressed in the following remarks:

Table 5 Center scores on each item, mean scores of centers, mean of lowest and highest performing centers, and total fidelity score for each center

\begin{tabular}{|c|c|c|c|c|c|c|c|c|c|}
\hline \multirow[t]{2}{*}{ IPS Fidelity Scale (IPS-25) } & \multirow{2}{*}{$\begin{array}{l}\text { Mean all } \\
\text { centers }\end{array}$} & \multicolumn{4}{|c|}{ Less performing centers } & \multicolumn{4}{|c|}{ High-performing centers } \\
\hline & & Center 1 & Center 2 & Center 4 & Mean & Center 3 & Center 5 & Center 6 & Mean \\
\hline Case load size & 5.0 & 5 & 5 & 5 & 5.0 & 5 & 5 & 5 & 5.0 \\
\hline Exclusively vocational services & 4.5 & 5 & 5 & 2 & 4.0 & 5 & 5 & 5 & 5.0 \\
\hline Vocational generalists & 4.6 & 4 & 5 & 5 & 4.7 & 5 & 4 & 5 & 4.5 \\
\hline Integration of IPS with treatment team & 3.6 & 5 & 2 & 2 & 3.0 & 4 & 5 & 4 & 4.2 \\
\hline IPS team contact with treatment team & 2.5 & 2 & 3 & 3 & 2.7 & 3 & 1 & 3 & 2.3 \\
\hline State vocational rehabilitation agency is actively involved & 4.3 & 3 & 5 & 5 & 4.3 & 5 & 4 & 4 & 4.3 \\
\hline IPS team forms a vocational unit & 4.8 & 5 & 5 & 4 & 4.7 & 5 & 5 & 5 & 4.8 \\
\hline Supervisory role of IPS team leader & 3.6 & 4 & 3 & 3 & 3.3 & 5 & 3 & 4 & 3.8 \\
\hline Zero exclusion of clients & 3.3 & 3 & 4 & 3 & 3.3 & 3 & 3 & 4 & 3.3 \\
\hline Agency focus on work & 2.6 & 2 & 3 & 3 & 2.7 & 3 & 2 & 3 & 2.5 \\
\hline Agency leadership support & 3.5 & 5 & 4 & 3 & 4.0 & 3 & 2 & 4 & 3.0 \\
\hline Benefits counseling & 4.8 & 4 & 5 & 5 & 4.7 & 5 & 5 & 5 & 5.0 \\
\hline Disclosure of disability to employers & 4.8 & 5 & 5 & 5 & 5.0 & 5 & 4 & 5 & 4.5 \\
\hline Individualized assessment & 4.7 & 5 & 5 & 5 & 5.0 & 4 & 4 & 5 & 4.3 \\
\hline Rapid search & 3.7 & 3 & 5 & 3 & 3.7 & 3 & 3 & 5 & 3.7 \\
\hline Individualized job search & 4.8 & 5 & 5 & 5 & 5.0 & 5 & 4 & 5 & 4.7 \\
\hline Job development, frequency & 1.8 & 1 & 2 & 1 & 1.3 & 3 & 1 & 3 & 2.2 \\
\hline Job development, quality & 3.7 & 2 & 1 & 4 & 2.3 & 5 & 5 & 5 & 5.0 \\
\hline Occupational diversity & 4.6 & 5 & 5 & 5 & 5.0 & 4 & 4 & 5 & 4.2 \\
\hline Employer diversity & 4.9 & 5 & 5 & 5 & 5.0 & 5 & 5 & 5 & 4.8 \\
\hline Competitive jobs & 3.6 & 4 & 5 & 1 & 3.3 & 5 & 3 & 4 & 3.8 \\
\hline Individualized supports & 4.5 & 4 & 5 & 5 & 4.7 & 3 & 5 & 5 & 4.3 \\
\hline Time-unlimited supports & 4.1 & 5 & 5 & 4 & 4.7 & 4 & 3 & 4 & 3.5 \\
\hline Community-based services & 1.2 & 1 & 1 & 1 & 1.0 & 1 & 1 & 2 & 1.3 \\
\hline Assertive outreach to clients & 3.9 & 5 & 5 & 2 & 4.0 & 4 & 3 & 5 & 3.8 \\
\hline Total fidelity score & & 97 & 103 & 89 & & 102 & 89 & 109 & \\
\hline
\end{tabular}


What we always have to challenge ourselves on is the use of time, considering time spent on internal meetings, participant meetings and employer contact. To obtain the optimal allocation of resources is pretty challenging.

Being an IPS specialist is a pretty complex and difficult role, where you are a seller on the one hand, selling the best manpower there is, next you're a facilitator, an IPS specialist, and you can sometimes have a therapeutic approach at times when the therapist is not there. So, it is a very difficult role, and it takes time to be secure in it.

Looking at the two items measuring "Integration with health services," which is an important IPS principle, the mean score of the two items across centers is 3. According to the quality thresholds defined by the program developers, this is barely above the "Fair fidelity" threshold [9]. These items measure whether the IPS specialists are integrated in participant's health treatment team, attend weekly meetings, and ensure focus on employment in coordinating services for the participant.

On the positive side, all six centers received top scores on the items "Caseload size" and "Employer diversity," and nearly top score on "Disclosure of disability to employers." "Caseload size" means that the caseload for each IPS specialist does not exceed 20 participants, in order to ensure close follow-up in all phases of the job search. "Employer diversity" refers to the diversity of workplaces where participants get jobs. It is used as an indicator of whether IPS specialists are following participants' own preferences, and not only working within the limits of their existing employer network. Disclosure measures whether IPS specialists provide information to participants about pros and cons of disclosing about their illness to an employer.

The effect evaluation showed that three of the six pilot centers performed particularly well on employment outcomes [32], though there were no obvious reasons for this. The top three centers did, however, differ from the rest on two particular fidelity items. They averaged 1.3 points above the average of the less performing centers on the item "Integration of IPS with treatment team," which is considered a crucial intervention component [3]. The challenges related to this topic were addressed frequently in the interviews and are illustrated by the following remark:

I think that it is the greatest success and the greatest challenge, that integration process (...), how we feel that they [treatment team] talk and feel concerning work.

However, the most striking difference was found between scores on "Job development-quality" (indicating quality of employer contact), where the top performing centers averaged 2.7 points above the average of the less performing centers. The issue of employer contact was addressed in the interviews, as exemplified in the following remarks:

...the job development part, that's something that for most of us, and definitely for me, has been new and different, going out and being assertive both on the phone and in person (...) After a while I realized it's been written in the manual the whole time, that we really need to have our main focus on job development. We've made some changes now this fall where we have set targets and try to reserve days and times to do that.

\section{Discussion}

The results indicate that the target population for the intervention was reached and indicate certain barriers and facilitators to participate and to implement IPS.

\section{Reach}

Participants' characteristics correspond to the specification of the pre-defined target group. However, the original IPS target group is people with severe mental illness. No differences in employment outcomes between people with moderate vs severe mental illness were found in the outcome study [15]. This may indicate that IPS is effective also for an extended target group. Some interesting points can be drawn from the characteristics of the study population. First, although all participants are in treatment for moderate to severe mental illness, mean level of health-related quality of life is on the upper half of the scale. This shows the importance of subjective measures of health and well-being for this target group. It is also worth noticing that education level is relatively low, and the frequency of adverse events in the past (violence, having been involuntarily committed) is high in the population. In spite of these characteristics, the intervention proved effective on employment outcomes, and participants found it useful even though the majority did not obtain employment.

\section{Barriers and facilitators to participate in IPS}

The role of the IPS specialist was perhaps the clearest facilitating factor emerging from both survey and interview data. Participants emphasized the availability of the IPS specialist, their attentiveness to participant preferences, and pushing participants to take steps out of the comfort zone. The consistent employment focus in the follow-up was important for participants' motivation and learning. This is in line with a study identifying emotional support, practical assistance, and a client-centered approach as effective ingredients from the participant 
perspective [33]. An ethnographic study of IPS specialist skills identified efficiency, good collaboration with partners, and developing egalitarian relationships with participants as skills differentiating successful specialists from less successful ones [34]. The findings in the current study aligns well with these results, but particularly highlights the consumer-oriented, empowering approach of the IPS specialists.

Another important facilitator, found in participant data as well as in fidelity reports, was the freedom of disclosure. The participants seemed to value the support and information regarding this topic. A previous study has found this item to correlate positively with employment outcomes [35].

The facilitating factors discussed above align well with the values of recovery ideology, which has inspired the development of IPS [4]. Central ideals, such as empowerment and functioning in valued roles are reflected in participants' reports, as well as being evident in the principles guiding the intervention.

This may partly explain why so many participants were very satisfied with the intervention and found it useful, despite the fact that at 18 months the majority (63\%) had not obtained employment [15]. However, the outcome evaluation showed that intervention participants reported lower levels of self-reported psychological distress and somatic symptoms, and increased levels of functioning, quality of life, and well-being (ibid). Moreover, satisfaction and usefulness may reflect changes in participants' orientation towards ordinary employment, and that they have gained useful knowledge and selfesteem in the job search process, as indicated by a recent meta-ethnographic review [36].

Few participants agreed to the barriers presented. Less than half of the respondents agreed that their illness was a barrier, which may be explained by the individual tailoring of the intervention, as expressed in participant interviews.

\section{Barriers and facilitators to implement IPS}

The barriers to implementation as indicated by fidelity reviews and interview data represent untraditional approaches to providing vocational services and are all related to the role of the IPS specialist. Providing community-based services has been reported as a challenge in other IPS studies [37-39], as well as a facilitator for employment outcomes [40], and thus seems to be an important, but challenging component that may take some time to develop.

Succeeding with job development was also indicated by fidelity data as a challenging, but important component. Job development is a far more assertive approach than traditional employment services [41], which is characterized by using subsidized employment, sheltered employment, and work practice. The quality of job development efforts may indicate a make-or-break point for success [42, 43].

As for integration with health services, this is a core principle in IPS and indicated in the literature as crucial for successful implementation [3]. Barriers to integration seem to be rooted in structural barriers, cultural differences in institutions, and attitudes [36, 41, 44, 45].

Two facilitators are reflected in both populations in the current study, which also diverge from traditional follow-up. First, disclosure is often not a topic in traditional services, as the service provider usually makes the initial employer contact, directly or indirectly revealing participants' health issues. Second, the IPS specialist has the capacity to provide individualized follow-up due to a smaller caseload than in traditional services. Furthermore, s/he acts as a mediating link between the job seeker and the employer, through job matching and by increasing access to a variety of jobs. These facilitators enable individualized tailoring of the follow-up, which is likely to enhance participants' motivation and sense of autonomy, and thus may create sustainable workforce participation through a good job match.

\section{Strengths and limitations}

Strengths of the study are its structured and mixed methods approach, with defined measures. This has enabled a thorough and multi-faceted evaluation of the intervention and enabled an integration of quantitative and qualitative findings. Compared to most other IPS evaluations, it provides richer data material from which to draw conclusions and identify areas for future research.

One limitation pertains to the validity of the fidelity reviews. It is recommended that reviewers are independent [46], which they were not in this study. However, this does not seem to be uncommon [13, 47-49]. Moreover, some IPS specialists questioned the training of the evaluators in the initial phase. Another limitation lies in the participant interviews, as far more satisfied participants than dissatisfied ones agreed to be contacted, leading to selection bias. Finally, the steps taken to collate the quantitative and qualitative results served the purpose of distilling large amounts of data; however, performing these steps with an inductive approach would likely have emphasized other parts of the data, which readers should keep in mind.

\section{Conclusions}

Various facilitators and barriers to participate in and implement IPS were identified in the current study. For participants, the IPS specialist seemed to play a crucial role, as did the freedom to disclose or not. Barriers to participation were difficult to detect. One's illness was not seen as a barrier for most participants, which strengthens the legitimacy of offering IPS to this 
population. Barriers to implement IPS included providing community-based services, employer contact, and integrating services, while facilitators to implementation included the fulfillment of the IPS specialist role, freedom of disclosure, and caseload size. Job development also seemed to be an important, but challenging component to implement. The novelty of the mentioned components in IPS may explain why they are challenging to implement, while clearly meeting a need among participants. As evidence on the effect of IPS increases, measures should be undertaken to enable a weighting of the different fidelity items [50], identifying crucial components of the intervention. This can facilitate more effective implementation of the intervention across contexts and possibly enhance its effect on employment outcomes.

\section{Supplementary information}

Supplementary information accompanies this paper at https://doi.org/10. 1186/s43058-020-00083-9.

Additional file 1. Qualitative themes.

\section{Abbreviations}

IPS: Individual Placement and Support; TAU: Treatment as usual; WHO: World Health Organization

\section{Acknowledgements}

The authors wish to thank all study participants, who enabled the study.

\section{Authors' contributions}

All authors edited all manuscript drafts. TF drafted and conducted the quantitative data collection, drafted the manuscript, and contributed in the interview analyses. KL conducted and analyzed the interviews. SE was the PI and played a crucial role in the design of the study and data collection. FS contributed with expertise on supported employment and process evaluations. All authors read and approved the final manuscript.

\section{Funding}

The study was funded by the Norwegian Directorate of Health and the Directorate of Labor and Welfare.

\section{Availability of data and materials}

The datasets generated in the study are not publicly available due to restrictions imposed on data sharing by the Norwegian Social Science Data Services.

\section{Ethics approval and consent to participate}

The study complied with the Helsinki Declaration. The process evaluation was part of an outcome evaluation, described in a published protocol [25], which was approved by the Norwegian Social Science Data Services (project no. 34989, approved on 4 October 2013). Written informed consent was obtained from all patients included in the study. Service providers received written information, and verbal consent was given (verbal consent was sufficient at the time as no personal or identifying information was collected).

\section{Consent for publication}

Not applicable.

\section{Competing interests}

The authors declare that they have no competing interests.

\section{Author details}

'NORCE Norwegian Research Centre, Postboks 7810, 5020 Bergen, Norway. ${ }^{2}$ Department of Pedagogy, Religion and Social Studies, Western Norway University of Applied Sciences, Inndalsveien 28, 5063 Bergen, Norway. ${ }^{3}$ Department of Psychology, University of Oslo, Forskningsveien 3A, 0373 Oslo, Norway. ${ }^{4}$ Department of Public and Occupational Health, Amsterdam University Medical Centers, Amsterdam Public Health Research Institute, PO Box 7057, Amsterdam 1007 MB, The Netherlands.

Received: 21 January 2020 Accepted: 8 October 2020

Published online: 30 October 2020

\section{References}

1. Luciano A, Meara E. Employment status of people with mental illness: national survey data from 2009 and 2010. Psychiatr Serv. 2014;65(10):1201-9.

2. WHO. Mental health action plan 2013-2020. Geneva: World Health Organization; 2013.

3. Bond G. Supported employment: evidence for an evidence-based practice. Psychiatr Rehabil J. 2004;27(4):345.

4. Drake RE. A brief history of the Individual Placement and Support model. Psychiatr Rehabil J. 1998;22(1):3

5. Becker DR, Drake RE. A working life for people with severe mental illness. New York: Oxford University Press; 2003.

6. Becker DR, Swanson SJ, Reese SL, Bond GR, McLeman BM. Supported employment fidelity review manual; 2015.

7. Bond G, Becker D, Drake R. Measurement of fidelity of implementation of evidence-based practices: case example of the IPS Fidelity Scale. Clin Psychol Sci Pract. 2011;18(2):126-41.

8. Catty J, Lissouba P, White S, Becker T, Drake RE, Fioritti A, et al. Predictors of employment for people with severe mental illness: results of an international six-centre randomised controlled trial. Br J Psychiatry. 2008; 192(3):224-31.

9. Bond G, Peterson A, Becker D, Drake R. Validation of the revised individual placement and support fidelity scale (IPS-25). Psychiatr Serv. 2012;63(8):758-63.

10. de Winter L, Couwenbergh C, van Weeghel J, Bergmans C, Bond GR. Fidelity and IPS: does quality of implementation predict vocational outcomes over time for organizations treating persons with severe mental illness in the Netherlands? Soc Psychiatry Psychiatr Epidemiol. 2020. https://doi.org/10. 1007/s00127-020-01890-0.

11. Brinchmann B, Widding-Havneraas $T$, Modini M, Rinaldi M, Moe CF, McDaid D, et al. A meta-regression of the impact of policy on the efficacy of individual placement and support. Acta Psychiatr Scand. 2020; 141(3):206-20.

12. Bond G, Kim S, Becker D, Swanson S, Drake R, Krzos I, et al. A controlled trial of supported employment for people with severe mental illness and justice involvement. Psychiatr Serv. 2015;66(10):1027-34.

13. Heslin M, Howard L, Leese M, McCrone P, Rice C, Jarrett M, et al. Randomized controlled trial of supported employment in England: 2 year follow-up of the Supported Work and Needs (SWAN) study. World Psychiatry. 2011;10(2):132-7.

14. Oshima I, Sono T, Bond G, Nishio M, Ito J. A randomized controlled trial of individual placement and support in Japan. Psychiatr Rehabil J. 2014;37(2):137

15. Reme S, Monstad K, Fyhn T, Sveinsdottir V, Løvvik C, Lie S, et al. A randomized controlled multicenter trial of individual placement and support for patients with moderate-to-severe mental illness. Scand J Work Environ Health. 2018;45(1):33-41.

16. Suijkerbuijk Y, Schaafsma F, van Mechelen J, Ojajärvi A, Corbière $M$, Anema J. Interventions for obtaining and maintaining employment in adults with severe mental illness, a network meta-analysis: Cochrane Database Syst Rev; 2017.

17. Viering S, Jäger M, Bärtsch B, Nordt C, Rössler W, Warnke I, et al. Supported Employment for the reintegration of disability pensioners with mental illnesses: a randomized controlled trial. Front Public Health. 2015:3:237.

18. Glasgow R, Green L, Klesges L, Abrams D, Fisher E, Goldstein M, et al. External validity: we need to do more. Ann Behav Med. 2006;31(2):105-8.

19. Linnan L, Steckler A. Process evaluation for public health interventions and research. San Francisco: Jossey-Bass; 2002.

20. Oakley A, Strange V, Bonell C, Allen E, Stephenson J. Process evaluation in randomised controlled trials of complex interventions. BMJ. 2006: 332(7538):413-6. 
21. Bonfils I, Hansen H, Dalum H, Eplov L. Implementation of the individual placement and support approach-facilitators and barriers. Scand J Disabil Res. 2017;19(4):318-33.

22. Linnemørken LTB, Sveinsdottir $V$, Knutzen $T$, Rødevand L, Hernæs KH, Reme SE. Protocol for the Individual Placement and Support (IPS) in Pain Trial: a randomized controlled trial investigating the effectiveness of IPS for patients with chronic pain. BMC Musculoskelet Disord. 2018;19(1):47.

23. Sveinsdottir $V$, Lie $S A$, Bond GR, Eriksen HR, Tveito $T H$, Grasdal AL, et al. Individual placement and support for young adults at risk of early work disability (the SEED trial). A randomized controlled trial. Scand J Work Environ Health. 2019;45(1):33-41.

24. Bach-Mortensen AM, Lange BCL, Montgomery P. Barriers and facilitators to implementing evidence-based interventions among third sector organisations: a systematic review. Implement Sci. 2018;13(1):103.

25. Sveinsdottir V, Løvvik C, Fyhn T, Monstad K, Ludvigsen K, Øverland S, et al. Protocol for the effect evaluation of Individual Placement and Support (IPS): a randomized controlled multicenter trial of IPS versus treatment as usual for patients with moderate to severe mental illness in Norway. BMC Psychiatry. 2014;14(1):307.

26. Moore G, Audrey S, Barker M, Bond L, Bonell C, Hardeman W, et al. Process evaluation of complex interventions: Medical Research Council guidance. BMJ. 2015;350:h1258.

27. Johnson R, Onwuegbuzie A. Mixed methods research: a research paradigm whose time has come. Educ Res. 2004;33(7):14-26.

28. Palinkas LA, Aarons GA, Horwitz S, Chamberlain P, Hurlburt M, Landsverk J. Mixed method designs in implementation research. Adm Policy Ment Health Ment Health Serv Res. 2011;38(1):44-53.

29. Sheehan DV, Lecrubier $Y$, Sheehan $\mathrm{KH}$, Amorim P, Janavs J, Weiller $E$, et al. The Mini-International Neuropsychiatric Interview (MINI): the development and validation of a structured diagnostic psychiatric interview for DSM-IV and ICD-10. J Clin Psychiatry. 1998;59(Suppl 20):22-3.

30. Boyatzis RE. Transforming qualitative information: thematic analysis and code development. Thousand Oaks: SAGE; 1998.

31. Joffe H, Yardley L. Content and thematic analysis. In: Marks IDF, Yardley L, editors. Research methods for clinical and health psychology. London: SAGE Publications; 2004. p. 56-68.

32. Reme S, Monstad K, Fyhn T, Øverland S, Ludvigsen K, Sveinsdottir V, et al. Effektevaluering av Individuell jobbstøtte (IPS): sluttrapport. Bergen: Uni Research; 2016.

33. Johnson R, Floyd M, Pilling D, Boyce M, Grove B, Secker J, et al. Service users' perceptions of the effective ingredients in supported employment. J Ment Health. 2009;18(2):121-8.

34. Glover CM, Frounfelker RL. Competencies of more and less successful employment specialists. Community Ment Health J. 2013;49(3):311-6.

35. Cook J, Mulkern V, Grey D, Burke-Miller J, Blyler C, Razzano L, et al. Effects of local unemployment rate on vocational outcomes in a randomized trial of supported employment for individuals with psychiatric disabilities. J Vocat Rehabil. 2006;25(2):71-84.

36. Moen $E \AA$, Walseth $L T$, Larsen IB. Experiences of participating in individual placement and support: a meta-ethnographic review and synthesis of qualitative studies. Scand J Caring Sci. 2020. https://doi.org/10.1111/scs.12848.

37. Cocks E, Boaden R. Evaluation of an employment program for people with mental illness using the Supported Employment Fidelity Scale. Aust Occup Ther J. 2009;56(5):300-6.

38. Oldman J, Thomson L, Calsaferri K, Luke A, Bond G. A case report of the conversion of sheltered employment to evidence-based supported employment in Canada. Psychiatr Serv. 2005;56(11):1436-40.

39. van Erp N, Giesen F, van Weeghel J, Kroon H, Michon H, Becker D, et al. A multisite study of implementing supported employment in the Netherlands. Psychiatr Serv. 2007;58(11):1421-6.

40. Becker D, Smith J, Tanzman B, Drake R, Tremblay T. Fidelity of supported employment programs and employment outcomes. Psychiatr Serv. 2001; 52(6):834-6.

41. Shepherd G, Lockett H, Bacon J, Grove B. Establishing IPS in clinical teamsSome key themes from a national implementation programme. J Rehabil. 2012;78(1):30-36.

42. Leff H, Cook J, Gold P, Toprac M, Blyler C, Goldberg R, et al. Effects of job development and job support on competitive employment of persons with severe mental illness. Psychiatr Serv. 2005;56(10):1237-44.

43. Carlson L, Smith G, Rapp C. Evaluation of Conceptual Selling ${ }^{\oplus}$ as a job development planning process. Psychiatr Rehabil J. 2008;31(3):219.
44. Marwaha S, Balachandra S, Johnson S. Clinicians' attitudes to the employment of people with psychosis. Soc Psychiatry Psychiatr Epidemiol. 2009;44(5):349.

45. Killackey E, Waghorn G. The challenge of integrating employment services with public mental health services in Australia: progress at the first demonstration site. Psychiatr Rehabil J. 2008;32(1):63-6.

46. Bond G, Drake R, Becker D. Generalizability of the Individual Placement and Support (IPS) model of supported employment outside the US. World Psychiatry. 2012;11(1):32-9.

47. Gold P, Meisler N, Santos A, Carnemolla M, Williams O, Keleher J. Randomized trial of supported employment integrated with assertive community treatment for rural adults with severe mental illness. Schizophr Bull. 2006;32(2):378-95.

48. Metcalfe J, Drake R, Bond G. Economic, labor, and regulatory moderators of the effect of Individual Placement and Support among people with severe mental illness: a systematic review and meta-analysis. Schizophr Bull. 2017; 44(1):22-31.

49. Vukadin M, Schaafsma FG, Westerman MJ, Michon HWC, Anema JR. Experiences with the implementation of Individual Placement and Support for people with severe mental illness: a qualitative study among stakeholders. BMC Psychiatry. 2018;18(1):145.

50. Latimer E. An effective intervention delivered at sub-therapeutic dose becomes an ineffective intervention. Br J Psychiatry. 2010;196(5):341-2.

\section{Publisher's Note}

Springer Nature remains neutral with regard to jurisdictional claims in published maps and institutional affiliations.
Ready to submit your research? Choose BMC and benefit from:

- fast, convenient online submission

- thorough peer review by experienced researchers in your field

- rapid publication on acceptance

- support for research data, including large and complex data types

- gold Open Access which fosters wider collaboration and increased citations

- maximum visibility for your research: over $100 \mathrm{M}$ website views per year

At BMC, research is always in progress.

Learn more biomedcentral.com/submissions 